American Journal of Biochemistry and Biotechnology 6 (3): 172-180, 2010

ISSN 1553-3468

(C) 2010 Science Publications

\title{
Endothelial Dysfunction and Insulin Resistance as Pathophysiologic Mechanisms in a Rat Model of Preeclampsia
}

\author{
${ }^{1}$ Ayman Z. Elsamanoudy and ${ }^{2}$ Amr M. Abbas \\ ${ }^{1}$ Department of Medical Biochemistry, \\ ${ }^{2}$ Department of Medical Physiology, \\ Faculty of Medicine, Mansoura University, Egypt
}

\begin{abstract}
Problem statement: To assess the plasma concentrations and placental gene expression of soluble fms like tyrosine kinase (sFlt-1), Vascular Endothelial Growth Factor (VEGF), visfatin and Tumour Necrosis Factor $\alpha(\mathrm{TNF} \alpha)$ in a rat model of preeclampsia, induced by chronic Reduction of Uterine Perfusion Pressure (RUPP) and to investigate the involvement of Insulin Resistance (IR) in the pathophysiology of preeclampsia and the possible relation of visfatin and TNF $\alpha$ to IR in preclampsia. Approach: Twenty female Sprague-Dawley rats weighing 220-250 g were divided into either RUPP $(\mathrm{n}=10)$ or Normal Pregnant $(\mathrm{NP} ; \mathrm{n}=10)$ (control) groups. Plasma levels and placental gene expression of sFlt-1, VEGF, visfatin, TNFa, plasma endothelin (ET-1), glucose, serum insulin, creatinine, HOMA-IR and placental Malondialdehyde (MDA) and total antioxidants were measured. Also, Mean Arterial Pressure (MAP), fetal number and weight were determined. Results: In RUPP rats, MAP increased, plasma level and placental gene expression of sFlt-1, visfatin and $\mathrm{TNF} \alpha$ increased while those of VEGF decreased. Moreover, plasma ET-1, glucose, insulin, HOMA-IR increased while GFR, fetal weight and number decreased. There is a significant positive correlation between TNF $\alpha$, ET-1, sFlt-1 and MAP, between plasma visfatin or TNF $\alpha$ levels and both serum insulin and HOMA-IR, between visfatin and TNF $\alpha$, between TNF $\alpha$ and ET-1 and between placental MDA and either sFlt-1 or ET-1. Furthermore, a negative correlation was reported between VEGF and MAP. Conclusion: RUPP increased sFlt-1, TNF $\alpha$ and decreased VEGF resulting in endothelial dysfunction which is manifested by increased MDA and ET-1. This results in altered renal function and hypertension. Moreover, IR may be involved in the pathophysiology of preeclampsia. Visfatin and $\mathrm{TNF} \alpha$, may have a role in IR during preclampsia.
\end{abstract}

Key words: Angiogenesis, endothelial dysfunction, insulin resistance, oxidative stress, preeclampsia, rat

\section{INTRODUCTION}

Preeclampsia is a major obstetric problem and a significant source of maternal and neonatal morbidity and mortality. Although preeclampsia continues to affect about $8 \%$ of all pregnancies, the incidence of preeclampsia has seen a $40 \%$ increase in recent years (Roberts et al., 2003). Although preeclampsia has been well characterized, with many studies indicating that proteinuria, edema, endothelial cell dysfunction and insufficient placentation are all hallmarks of this disorder, the mechanisms underlying the pathogenesis of this dreaded condition remain obscure. The continuing uncertainties regarding the mechanisms underlying the pathogenesis of preeclampsia are at least in part attributable to the difficulties in performing mechanistic studies in pregnant women (Granger et al., 2006). Thus, the continued characterization and development of animal models for mechanistic research of preeclampsia remains an important endeavor.

There is an imbalance between proangiogenic and antiangiogenic factors, such as Vascular Endothelial Growth Factor (VEGF) and soluble fms-like tyrosine kinase-1 (sFlt-1) in preeclampsia (Lu et al., 2007). This dysregulation of angiogenic factors may be important in the pathogenesis of preeclampsia (Lu et al., 2007).

The Insulin Resistance (IR) syndrome is comprised of a cluster of metabolic abnormalities that confer increased risk of diabetes, hypertension and cardiovascular disease (Grinspoon, 2006). Several features of the IR syndrome, such as obesity, hypertension, dyslipidemia, systemic inflammation and

Corresponding Author: Amr M. Abbas, Department of Medical Physiology, Faculty of Medicine, Mansoura University, Egypt Tel: 0020502240747/0020101545048 
impaired fibrinolysis, are also associated with preeclampsia. In addition, women with polycystic ovary syndrome or gestational diabetes, two disorders characterized by IR, are at increased risk of preeclampsia. Collectively, these data suggest that IR may contribute to the pathogenesis of preeclampsia (Wolf et al., 2002). Convincing evidence has been presented that fat-secreted proteins profoundly influence insulin sensitivity and energy metabolism (Fasshauer and Paschke, 2003). Furthermore, various studies suggest that these adipokines (as TNF $\alpha$ ) play an important role in the pathogenesis of preeclampsia (Conrad et al., 1998; Alhusseini et al., 2010). Visfatin is a novel adipokine that mimics the insulin actions, improves glucose tolerance and might play a role in the development of obesity-associated IR and type 2 diabetes mellitus (Fukuhara et al., 2005).

Therefore, the aim of this study was to assess the plasma concentrations and placental gene expression of sFlt-1, VEGF, visfatin and TNFa in a rat model of preeclampsia induced by chronic Reduction of Uterine Perfusion Pressure (RUPP). Moreover, the current study aimed to investigate the involvement of IR in the pathophysiology of preeclampsia and the possible relation of visfatin and TNF $\alpha$ to IR in such disease.

\section{MATERIALS AND METHODS}

Animals: Twenty female Sprague-Dawley rats weighing 220-250 g were used in the present study. They were purchased from Vaccine and Immunization Authority (Helwan, Cairo, Egypt) and housed (Animal House, Medical Physiology department, Faculty of Medicine, Mansoura University, Egypt) under controlled conditions (temperature $23 \pm 1^{\circ} \mathrm{C}$ and a $12: 12$ light/dark cycle). The animals were allowed free access to standard rat chow and tap water. The female rats were mated with male rats (275-300 g) and pregnant females were isolated from the males. On day 14 of gestation, rats were randomly divided into either RUPP $(n=10)$ or Normal Pregnant (NP; $n=10)$ (control) groups. All experimental procedures of the present study were approved by the Medical Research Ethics Committee of Mansoura University, Egypt.

RUPP procedure: All rats undergoing surgical procedures were anesthetized with $2 \%$ isoflurane. Pregnant rats entering the RUPP group underwent the following clipping procedure at 14 days of gestational age. After a midline incision, the lower abdominal aorta was isolated and a silver clip (0.203 mm ID) was placed around the aorta above the iliac bifurcation. Silver clips (0.100 mm ID) were also placed on branches of both the right and left ovarian arteries that supply the uterus, whereas NP rats underwent a sham procedure (Gilbert et al., 2007).

Sampling: At day 20 of gestation, blood samples were obtained from the rat tail vein under ether anesthesia and divided into two tubes: the first one containing $\mathrm{K}_{2}$ EDTA, mixed well, centrifuged at $7000 \mathrm{rpm}$ for 10 min to obtain plasma which was stored at $-30^{\circ} \mathrm{C}$ until assay of endothelin, sFLT-1, VEGF, TNF $\alpha$, visfatin and glucose. Blood in the second tube was collected without anticoagulant, left for $30 \mathrm{~min}$ for coagulation and then centrifuged for $10 \mathrm{~min}$ at $4000 \mathrm{rpm}$ to obtain serum which was stored at $-20{ }^{\circ} \mathrm{C}$ until assay of creatinine and insulin. Moreover, rats were housed in metabolic cages for 24 hours to collect urine samples for measurement of urinary creatinine and protein concentrations.

Conceptus measurements: The uterus was exteriorized, the number of viable and resorbed pups was counted and the pups were weighed. The placentae were collected from each uterine horn, snap frozen in liquid nitrogen and stored at $-80^{\circ} \mathrm{C}$ until biochemical analysis of MDA, antioxidants and performing RT-PCR for gene expression.

Biochemical investigations: Plasma glucose was quantitated by glucose oxidase-peroxidase method (Barham and Trinder, 1972, Alhusseini et al., 2010). Serum insulin (Ultra Sensitive Rat Insulin ELISA Kit, Crystal Chem INC, Spain, Cat. No. 90060), plasma sFlt-1 (DuoSet ELISA kit, R\&D systems, USA, Cat. No., DY471), VEGF (Quantikine ELISA kit, R\&D systems, USA, Cat. No., RRV00), visfatin (ELISA kit, RayBiotech Inc., USA, Cat. No., EIA-VIS-1), TNF $\alpha$ (ELISA kit, Thermo Scientific, USA, Cat. No., ER3TNFA), endothelin (EIA kit, Cayman, USA, Cat. No., 583151) were measured according to manufacturer instructions, employing sandwich ELISA method. Plate reader (Tecan, SunRise Absorbance reader) was used for reading. Creatinine in serum and urine were assayed with colorimetric kits. Glomerular Filtration Rate (GFR) was determined by Creatinine Clearance $(\mathrm{CrCl})$. Urinary protein concentration was determined with a Sigma Protein Determination kit (P5656, Sigma Chemical $\mathrm{Co}$ ) according to manufacturer instructions.

Placental tissue homogenate preparation: Placentae were perfused with a PBS (phosphate buffered saline) solution, pH 7.4 containing $0.16 \mathrm{mg} \mathrm{mL}^{-1}$ heparin to remove any red blood cells and clots. Then, they were homogenized in 5-10 mL cold buffer. Homogenates were centrifuged at $10000 \mathrm{rpm}$ for $15 \mathrm{~min}$ at $4^{\circ} \mathrm{C}$ and 
the supernatant was kept at $-80^{\circ} \mathrm{C}$ until assay of lipid peroxides (Malondialdehyde, MDA) and total antioxidants. MDA was analyzed by measuring the production of Thiobarbituric Acid Reactive Substances (TBARS) using colorimetric kit (Bio-Diagnostics, Egypt, Cat. No., MD 2528). Total antioxidants were determined using colorimetric kit (Bio-Diagnostics, Egypt, Cat. No., MD 2528).

Calculation of insulin sensitivity indexes HOMAIR index was calculated as an estimate of insulin sensitivity. It was calculated, analogous to the assumptions applied in the development of HOMA-IR in humans (Matthews et al., 1985), using the following equation: HOMA-IR $=($ FPG X FSI $) / 2.430$ (Cacho et al., 2008; Zareian et al., 2010).

RT-PCR: Total RNA extraction was carried out from rat placenta, after homogenization, using TriFast TM reagent (PeqLab. Biotechnologie $\mathrm{GmbH}$, Carl-Thiersch St. 2B 91052 Erlongen, Germany, Cat. No. 30-2010) according to the manufacturer's instructions. The remaining DNA was removed by digestion with DNase I (Sigma). Semiquantitative Reverse Transcription Polymerase Chain Reaction (RT-PCR) was performed using Ready-to-Go. RT-PCR beads for first cDNA synthesis and PCR reaction provided by Amersham Biosciences, England. Cat. No. 27-9266-01, according to the method of Berchtold (1989).

Gene specific primers used were: Gene specific primers were purchased from Biolegio. BV, PO Box 91, 5600 AB Nijmegen, Netherlands. sFlt-1 (VEGF R1): F-5 -CCAAAGCAATTCCCATGC-3`, R-5`-GTA GCC ACG AGTCAAATAGCG-3` (Graepler et al., 2005), TNF $\alpha$ : F-5 -ACAAGCCTGTAGCCCATGTT3', R-5 'AAAGTA GAC CTG C C CAGACT-3 (Netea et al., 1996), VEGF: F-5'-GCA CCC ATG GCA GAA GGA G-3', R-5'-TTC TTG TCT TGC TCT ATC TTT CTT TGG-3' (Li et al., 2005), Visfatin: F-5 GGGAAAGACCATGAGAAAGA-3`, R-5`AAGGCC ATTG GTTA CAACAT-3` (Choi et al., 2007), GAPDH (Internal control, house keeping gene): F-5'AAAGGGTCATCATCTCCGC-3', R-5' GGATGACCTTGCCCACAG-3' (Graepler et al., 2005).

Thermal cycling reaction was performed using thermal cycler (Minicycler PTC-150) with the following program: Initial denaturation: $94^{\circ} \mathrm{C}$ for 5 min, 30 cycles of $94^{\circ} \mathrm{C}$ for 0.5 min denaturation, $60^{\circ} \mathrm{C}$ for $1 \mathrm{~min}(\mathrm{sFlt}-1), 55^{\circ} \mathrm{C}$ for $30 \mathrm{sec}(\mathrm{TNF} \alpha), 55^{\circ} \mathrm{C}$ for 1 $\min (\mathrm{VEGF}), 51^{\circ} \mathrm{C}$ for $1 \mathrm{~min}$ (Visfatin) and $60^{\circ} \mathrm{C}$ for 1 min (GAPDH) as primer annealing, $72^{\circ} \mathrm{C}$ for $1 \mathrm{~min}$ extension and Final extension at $72^{\circ} \mathrm{C}$ for $7 \mathrm{~min}$. The products was subjected to agarose gel electrophoresis using 2\% agarose stained with ethidium bromide and visualized via light UV Transilluminator (Model TUV20, OWI. Scientific, Inc. 800 242-5560) and photographed under fixed conditions (the distance, the light and the zoom) The RT-PCR products size were as follow: 316, 427, 360, 468 and 315 bp for sFlt-1, TNF $\alpha$, VEGF, Visfatin and GAPDH (internal control-house keeping gene) respectively. The results photos were analyzed with scion image (B release Alpha 4.0.3.2. Software for windows ${ }^{\circledR}$ which performs bands detection and conversion to peaks. Area under each peak were calculated in square pixels and used for quantification. Gene expression levels were determined by calculating the ratio between the square pixel value of the target gene in relation to the control gene (house keeping gene).

Statistical analysis: data were given as mean \pm SD and analyzed using SPSS, version 10. $\mathrm{p}<0.05$ is significant.

\section{RESULTS}

While basal Blood Pressure (BP) showed non significant change in both Normal Pregnant (NP) (control) and RUPP rats, final BP, measured at day 19 of gestation, is significantly increased in RUPP group compared with the NP rats $(\mathrm{p}<0.05)$ as shown in Table 1. Also, protein excretion in urine increased and creatinine clearance (GFR) decreased significantly in RUPP rats relative to control group $(\mathrm{p}<0.05)$ (Table 1).

Fasting plasma glucose, fasting serum insulin, HOMA-IR as well as plasma and gene expression of visfatin (Fig. 4) were increased in RUPP rats compared with NP rats $(\mathrm{p}<0.05)$ (Table 1). Moreover, plasma and gene expression of sFlt-1 (Fig. 1) and TNFa (Fig. 2) increased while those of VEGF (Fig. 3) decreased in RUPP rats relative to control NP group $(\mathrm{p}<0.05)$ (Table 1).

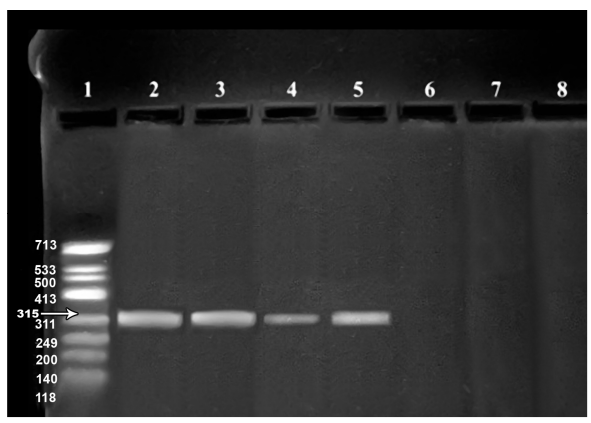

Fig. 1: RT-PCR product of sFlt-1 gene expression: (1) DNA marker; (2) sFlt-1gene in NP rats; (3) sFlt-1 gene of RUPP rats; (4) GAPDH gene of NP rats; (5) GAPDH gene of RUPP rats; (6) negative control 
Am. J. Biochem. \& Biotech., 6 (3): 172-180, 2010

Table 1: Mean Arterial Pressure (MAP), biochemical parameters, placental gene expression and conceptus morphometricus in Reduced Uterine Perfusion Pressure (RUPP) pregnant and Normal Pregnant (NP) rats

\begin{tabular}{|c|c|c|}
\hline Parameters & Normal pregnant rat (control group) & RUPP pregnant rats (preclamptic group) \\
\hline \multicolumn{3}{|l|}{ MAP (mmHg) } \\
\hline Baseline MAP (mmHg) & $107.00 \pm 5.00$ & $105.00 \pm 5.00$ \\
\hline Final MAP $(\mathrm{mmHg})$ & $103.00 \pm 4.00$ & $129.00 \pm 6.00^{\mathrm{a}}$ \\
\hline \multicolumn{3}{|l|}{ Biochemical parameters } \\
\hline Urinary proteins $(\mathrm{mg} / 24 \mathrm{~h})$ & $15.00 \pm 2.00$ & $107.00 \pm 9.00^{\mathrm{a}}$ \\
\hline $\operatorname{GFR}(\mathrm{Ccr})\left(\mathrm{mL} \mathrm{min}{ }^{-1}\right)$ & $2.21 \pm 0.14$ & $1.29 \pm 0.22^{\mathrm{a}}$ \\
\hline Plasma glucose $\left(\mathrm{mg} \mathrm{dL}^{-1}\right)$ & $91.50 \pm 1.80$ & $125.90 \pm 5.70^{\mathrm{a}}$ \\
\hline Serum insulin $\left(\mathrm{uU} \mathrm{mL} \mathrm{m}^{-1}\right)$ & $8.50 \pm 0.70$ & $13.50 \pm 0.80^{\mathrm{a}}$ \\
\hline HOMA-IR & $2.60 \pm 0.24$ & $4.90 \pm 0.21^{\mathrm{a}}$ \\
\hline Plasma visfatin $\left(\mathrm{ng} \mathrm{mL}^{-1}\right)$ & $0.33 \pm 0.02$ & 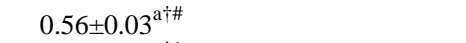 \\
\hline Plasma TNF $\alpha\left(\mathrm{pg} \mathrm{mL}^{-1}\right)$ & $8.10 \pm 1.10$ & $19.20 \pm 1.50^{\mathrm{a} \ddagger \dagger}$ \\
\hline Plasma sFlt-1 (pg mL $\left.{ }^{-1}\right)$ & $82.40 \pm 9.60$ & $665.30 \pm 18.60^{\mathrm{a} \text { 咅 }}$ \\
\hline Plasma free VEGF $\left(\mathrm{pg} \mathrm{mL}^{-1}\right)$ & $820.40 \pm 20.1$ & $410.60 \pm 15.80^{\mathrm{a} * \S}$ \\
\hline Plasma endothelin-1 (pg mL $\left.\mathrm{mL}^{-1}\right)$ & $1.67 \pm 0.20$ & $4.56 \pm 0.30^{\mathrm{a}: \#}$ \\
\hline Placental MDA (umol mg ${ }^{-1}$ protein) & $1.78 \pm 0.21$ & $3.61 \pm 0.26^{\mathrm{a} o \mathrm{~s}}$ \\
\hline Total antioxidants $\left(\mathrm{mmol} \mathrm{L}^{-1}\right)$ & $0.33 \pm 0.01$ & $0.16 \pm 0.05^{\mathrm{a}}$ \\
\hline \multicolumn{3}{|l|}{ Placental gene expression } \\
\hline TNF $\alpha$ gene expression & $0.50 \pm 0.02$ & $2.60 \pm 0.10^{\mathrm{a}}$ \\
\hline sFlt-1 gene expression & $0.70 \pm 0.08$ & $2.80 \pm 0.10^{\mathrm{a} \#}$ \\
\hline VEGF gene expression & $3.20 \pm 0.10$ & $0.90 \pm 0.07^{\mathrm{a} \S}$ \\
\hline Visfatin gene expression & $1.40 \pm 0.07$ & $4.90 \pm 0.10^{\mathrm{a} \#}$ \\
\hline \multicolumn{3}{|l|}{ Conceptus morphometrics } \\
\hline Fetal weight & $2.30 \pm 0.10$ & $1.90 \pm 0.10^{\mathrm{a}}$ \\
\hline Number of fetuses & $16.00 \pm 1.00$ & $6.00 \pm 1.00^{\mathrm{a}}$ \\
\hline
\end{tabular}

Values are given as mean \pm SD for groups of ten rats each. Values are statistically significant at $\mathrm{p}<0.05$. GFR: Glomerular Filtration Rate (creatinine clearance, Ccr); sFlt-1: Soluble fms like tyrosine kinase; VEGF: Vascular Endothelial Growth Factor; MDA: Malondialdehyde; ${ }^{\text {a }}$ Significant compared to NP group. Pearson correlation statistical analysis: ${ }^{\dagger}$ : Significant positive correlation with serum insulin and with HOMAIR; " Significant positive correlation with MAP; ${ }^{*}$ : Significant negative correlation with MAP; ${ }^{\#}$ : Significant positive correlation with TNF $\alpha$; Significant negative correlation with sFlt- $1 ;{ }^{\infty}$ : Significant positive correlation with sFlt-1; ${ }^{\sigma}$ : Significant positive correlation with endothelin

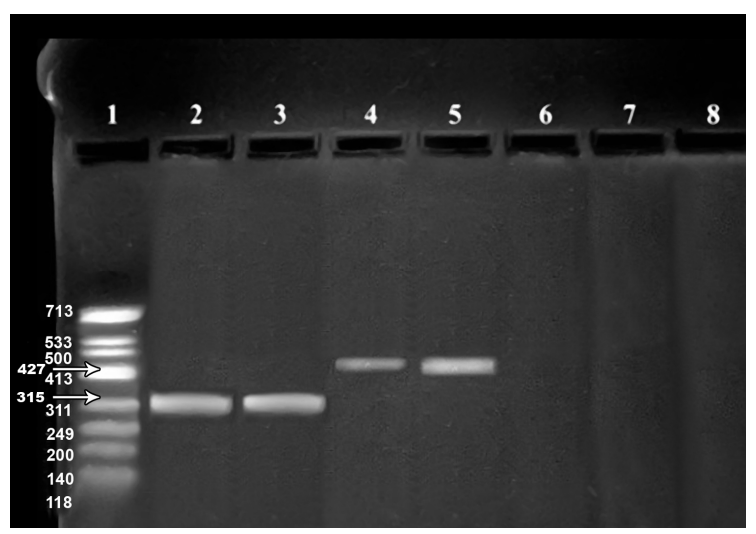

Fig. 2: RT-PCR product of TNF $\alpha$ gene expression: (1) DNA marker; (2) TNF $\alpha$ gene in NP rats; (3) TNF $\alpha$ gene of RUPP rats; (4) GAPDH gene of NP rats; (5) GAPDH gene of RUPP rats (6) negative control

Also, plasma endothlin and placental MDA were increased whereas total antioxidants were decreased significantly in RUPP group compared with control rats $(\mathrm{p}<0.05)$ as shown in Table 1.

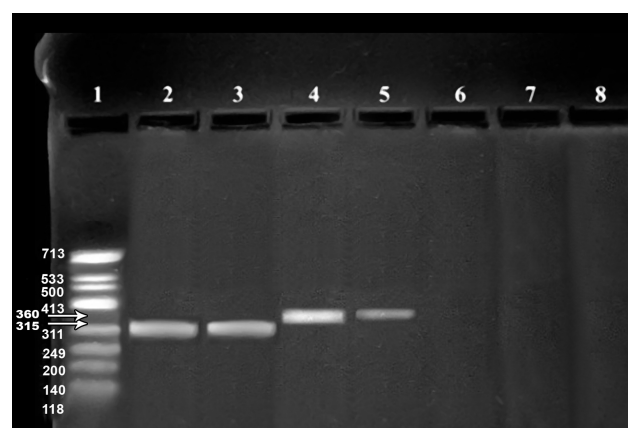

Fig. 3: RT-PCR product of VEGF gene expression: (1) DNA marker; (2) VEGF gene in NP rats; (3) VEGF gene of RUPP rats; (4) GAPDH gene of NP rats; (5) GAPDH gene of RUPP rats; (6): negative control

Table 1 showed that there is a significant positive correlation between TNF $\alpha$, endothelin or sFlt-1 and MAP $(\mathrm{p}<0.05)$ and a negative correlation between VEGF and MAP $(p<0.05)$. Moreover, a significant positive correlation $(\mathrm{p}<0.05)$ was reported between plasma visfatin or $\mathrm{TNF} \alpha$ level and both serum insulin and HOMA-IR as well as between visfatin and TNF $\alpha$. 




Fig. 4: RT-PCR product of Visfatin gene expression: (1) DNA marker; (2) Visfatin gene in NP rats; (3) Visfatin gene of RUPP rats; (4) GAPDH gene of NP rats; (5) GAPDH gene of RUPP rats; (6) negative control

Also, there is a significant positive correlation between $\mathrm{TNF} \alpha$ and endothelin as well as between placental MDA and either sFlt-1 or endothelin (Table 1).

Also, Table 1 showed that the number and weight of RUPP fetuses were significantly lesser than those of NP rats $(\mathrm{p}<0.05)$.

\section{DISCUSSION}

One of the leading theories concerning the cause of preeclampsia suggests a pathway starting with inadequate trophoblast invasion of maternal spiral arteries leading to decreased placental perfusion. This in turn leads to placental ischemia, resulting in placental release of factors, subsequent maternal endothelial dysfunction and then systemic vasoconstriction (Dekker and Sibai, 1998). Chronic reduction in uterine perfusion pressure in pregnant animals has been used to study potential mechanisms of human preeclampsia because it initiates the disorder at an early step in the cascade described above (Losonczy et al., 1992). The current study showed significant increase in MAP, at the 20th day of pregnancy, decrease in GFR and proteinuria in RUPP rats compared with NP rats (Table 1). These results were consistent with Alexander et al. (2001a), who reported that the RUPP model in the rats is characterized by hypertension and urinary protein excretion. Thus, the RUPP model in the rat has many features similar to those of humans with preeclampsia.

The current study showed a significant increase of plasma level and placental gene expression of TNF $\alpha$ in RUPP rats compared with NP rats (Table 1 and Fig. 2). Moreover, there was a positive correlation between TNF $\alpha$ and MAP (Table 1). Placental production rates of several cytokines are altered in preeclampsia. Elevated $\mathrm{TNF} \alpha$ expression and secretion by the preeclamptic placenta has been documented (Hung et al., 2004). Moreover, it was reported that serum TNF $\alpha$ increased in RUPP rats and chronic infusion of $\mathrm{TNF} \alpha$ into pregnant rats increases arterial pressure and decreases renal plasma flow and GFR (LaMarca et al., 2005a). These findings indicate that $\mathrm{TNF} \alpha$ may play a role in mediating the hypertension and reduction in renal hemodynamics observed during RUPP in pregnant rats. $\mathrm{TNF} \alpha$ has multiple actions on endothelial cells, including promoting coagulation and inflammatory responses (Granger, 2004) that are particularly relevant in preeclampsia. Within placental tissues, elevated $\mathrm{TNF} \alpha$ concentrations may also increased trophoblast apoptosis, leading to accelerated syncytial shedding (a potential trigger of endothelial damage) and impaired placental function (Huppertz and Kingdom, 2004).

The present study revealed increased plasma concentration and placental gene expression of sFlt-1 in the RUPP rats compared with NP rats (Table 1 and Fig. 1). These results were in agreement with Gilbert et al. (2007) who reported that maternal plasma and amniotic fluid concentrations of sFlt-1 were increased along with increased levels of immunoreactive sFlt-1 in the placenta of pregnant rats in which RUPP was induced. The present data demonstrated that RUPP is a stimulus for placental production and secretion of sFlt-1.

Moreover, results of this study showed that fetal number and weight were decreased in the RUPP rats relative to normal pregnant control rats (Table 1) which suggest an intrauterine growth restriction. These results were in agreement with previous studies in preeclamptic women (Sibai et al., 2005) and RUPP pregnant rats (Gilbert et al., 2007).

Furthermore, the current study demonstrated that placental gene expression and plasma VEGF are decreased in the RUPP rats compared with NP controls (Table 1 and Fig. 3). Also, there was a negative correlation between plasma and placental gene expression of VEGF and sFlt-1 (Table 1). These results were in agreement with previous studies on RUPP pregnant rats (Gilbert et al., 2007) and humans with preeclampsia (Maynard et al., 2003). It appears from these findings that decreased VEGF is a result of increased sFlt-1. Also, there was a positive correlation between sFlt-1 and MAP and a negative correlation between VEGF and MAP (Table 1), which suggest that increased sFlt-1 and decreased VEGF contributes to hypertension in preeclapmsia. These results were in agreement with Gilbert et al. (2007) and Lu et al. (2007). Animal studies suggest that antagonism of VEGF activity by sFlt-1 results in hypertension, 
proteinuria and glomerular endotheliosis, the classic lesion of preeclampsia (Maynard et al., 2003). Soluble Flt-1 in preeclamptic serum has been shown experimentally to inhibit VEGF-mediated angiogenesis; therefore, higher rates of sFlt-1 production and a decline in VEGF activity could be an explanation for the angiogenic abnormalities seen in preeclamptic pregnancies (Ahmad and Ahmed, 2004).

Also, results of this study demonstrated a positive correlation between plasma and placental gene expression of TNF $\alpha$ and sFlt-1 (Table 1). This suggests that increased TNF- $\alpha$ in preeclampsia is associated with elevated sFlt-1 level. Parrish et al. (2010) reported that in pregnant rats chronically treated with TNF- $\alpha$, plasma and placental levels of sFlt-1 increased, therefore they suggest that $\mathrm{TNF} \alpha$ may serve as an important stimulus for sFlt-1 production in response to placental ischemia.

The current study demonstrated increased plasma glucose and serum insulin levels and HOMA-IR in rats with preeclampsia (Table 1) which suggests development of IR in RUPP rats compared with NP rats. Increased IR is well established to be associated with preeclampsia (Thadhani et al., 2004). Elevated insulin increases sympathetic tone, muscle blood flow and vascular smooth muscle growth (Scherrer and Sartori, 1997).

Moreover, a positive correlation exists between plasma TNF $\alpha$ level and both serum insulin and HOMAIR (Table 1), which suggest that TNF $\alpha$ may play a role in IR in preeclampsia. Gulati (2005) suggested that the TNF-alpha is involved in preeclampsia and may have a role in gestational diabetes mellitus and IR. TNF- $\alpha$ inhibits insulin receptor signaling and insulin-regulated glucose uptake, suggesting that the IR may be mediated through this cytokine (Kirwan et al., 2002).

On the other hand, plasma and placental gene expression of visfatin were significantly increased in RUPP rats compared with NP control rats (Table 1 and Fig. 4). Fasshauer et al. (2008) reported that serum visfatin level is elevated in preeclampsia patients. In addition, plasma visfatin was positively correlated with TNF- $\alpha$ (Table 1). Ma et al. (2010) reported that the oversecretion of visfatin from placenta, probably induced by the elevated TNF- $\alpha$ level, contributes to the increased serum visfatin concentrations in women with gestational DM. Moreover, visfatin is positively correlated with both serum insulin and HOMA-IR, which suggest its possible involvement in pathogenesis of IR during preeclampsia (Table 1).

The current study also, revealed a significant increase in plasma Endothelin (ET-1) level in RUPP rats compared with NP rats. A positive correlation was reported between endothelin and either MAP or TNF- $\alpha$
(Table 1). These results indicate the involvement of the vasoconstrictor ET-1 in hypertension during preeclampsia and the association of increased ET-1 with elevated TNF- $\alpha$ in preeclampsia. Since endothelial damage is a known stimulus for ET-1 synthesis, increases in the production of endothelin may participate in the pathophysiology of preeclampsia (August and Lindheimer, 1995). Previously, Alexander et al. (2001b) showed that RUPP, in pregnant rats, elicited increased renal cortical and medullary expression of preproendothelin and that chronic administration of the selective Endothelin Type $\mathrm{A}\left(\mathrm{ET}_{\mathrm{A}}\right)$ receptor antagonist (ABT-627) markedly attenuates the increased MAP in these rats. In contrast, $\mathrm{ET}_{\mathrm{A}}$ receptor blockade had no significant effect on blood pressure in the normal pregnant animal, suggesting that ET-1 plays an important role in mediating the hypertension produced by chronic RUPP pregnant rats (Alexander et al., 2001b). Furthermore, a low-dose infusion of TNF- $\alpha$ increased ET-1 mRNA in the kidney, placenta and vasculature (LaMarca et al., 2005b). Collectively, these findings suggest that TNF- $\alpha$-induced hypertension in pregnant rats is mediated in part by endothelin, via $\mathrm{ET}_{\mathrm{A}}$ receptor activation.

Oxidative stress has been implicated in the pathophysiology of preeclapmsia because it damages the maternal vascular endothelium. Free radicals released from the poorly perfused fetoplacental unit initiate lipid peroxidation by attacking polyunsaturated fatty acids in cell membranes and converting them to Lipid Peroxides (LPOs) (Chappell et al., 1999). The present study showed that placental MDA significantly increased while total antioxidants were decreased in RUPP rats as compared to NP rats (Table 1). Sedeek et al. (2008) showed that RUPP in rats caused placental ischemia-induced hypertension which is associated with increased markers of oxidative stress in plasma and placenta (as placental MDA and superoxide production) and decreased plasma total antioxidant status as compared to NP rats. Taken together, these observations suggest that placental ischemia results in generalized oxidative stress in the RUPP model.

Also, results of the present study revealed that there was a positive correlation between placental MDA and either plasma sFlt-1 or endothelin (Table 1). Bridges et al. (2009) reported that chronic infusion of sFlt-1 to mimic the increase observed in preeclamptic patients would reduce plasma VEGF concentrations, increase Blood Pressure (BP) and vascular superoxide levels and cause vascular endothelial dysfunction in the pregnant rat. These data indicate that elevated maternal sFlt-1 and decreased VEGF concentrations results in increased oxidative stress which contributes to vascular 
dysfunction during pregnancy which in turn may leads to hypertension. Moreover, Fiore et al. (2005) demonstrated that ET-1, at concentrations corresponding to values in plasma from preeclamptic women, stimulates the secretion of oxidative stress molecules, such as MDA and simultaneously reduces the production of antioxidant molecules, such as GSH by placental trophoblast cells. Thus endothelin may have additional effects on the maternal cardiovascular system not only by direct actions on the vasculature but also indirectly via oxidative stress. Sedeek et al. (2008) showed that a positive feedback loop may exist in which ET-1 both stimulates and is stimulated by oxidative stress.

\section{CONCLUSION}

RUPP and placental ischemia may lead to increased sFlt-1, TNF $\alpha$ and decreased VEGF resulting in endothelial dysfunction which is manifested by increased MDA and ET-1, that in turn produce altered renal function and hypertension. Moreover, IR may be involved in the pathophysiology of preeclampsia. Increased visfatin and $\mathrm{TNF} \alpha$, may have a role in IR during preclampsia.

\section{RECOMMENDATION}

As IR is a risk factor for preeclampsia, therefore, simple assessments of IR, based on a single determination of fasting insulin and glucose, can predict preeclampsia in pregnant women. Also, controlling IR, obesity and other parameters of metabolic syndrome is recommended to decrease the risk of preeclampsia.

\section{REFERENCES}

Ahmad, S. and A. Ahmed, 2004. Elevated placental soluble vascular endothelial growth factor receptor1 inhibits angiogenesis in preeclampsia. Circ. Res., 95: 884-891. DOI: 10.1161/01.RES.0000147365.86159.f5

Alexander, B.T., S.E. Kassab, M.T. Miller, S.R. Abram and J.F. Reckelhoff et al., 2001a. Reduced uterine perfusion pressure during pregnancy in the rat is associated with increases in arterial pressure and changes in renal nitric oxide. Hypertension, 37: 1191-1195. PMID: 11304523

Alexander, B.T., A.N. Rinewalt, K.L. Cockrell, M.B. Massey and W.A. Bennett et al., 2001b. Endothelin type a receptor blockade attenuates the hypertension in response to chronic reductions in uterine perfusion pressure. Hypertension, 37: 485-489. PMID: 11230323
Alhusseini, N.F., N.A. Belacy, E.M. Kasem and M.M. Allam, 2010. Effect of exercise training on adiponectin receptor expression and insulin resistance in mice fed a high fat diet. Am. J. Biochem. Biotechnol., 6: 77-83. http://www.scipub.org/fulltext/ajbb/ajbb6277-83.pdf

August, P. and M.D. Lindheimer, 1995. Pathophysiology of Preeclampsia. In: Hypertension, Laragh, J. and B.M. Brenner (Eds.). Raven Press, New York, pp: 2407-2426.

Barham, D. and P. Trinder, 1972. An improved color reagent for the determination of blood glucose by oxidase system. Analyst, 97: 142-145. DOI: 10.1039/AN9729700142

Berchtold, M.W., 1989. A simple method for direct cloning and sequencing cDNA by the use of a sinle specific oligonucleotide and oligo (dT)in a Polymerase Chain Reaction (PCR). Nucleic Acids Res., 17: 453-453. PMID: 2911482

Bridges, J.P., J.S. Gilbert, D. Colson, S.A. Gilbert and M.P. Dukes et al., 2009. Oxidative stress contributes to soluble fms-like tyrosine kinase-1 induced vascular dysfunction in pregnant rats. Am. J. Hypertens., 22: 564-568. PMID: 19265787

Cacho, J., J. Sevillano, J. de Castro, E. Herrera and M.P. Ramos, 2008. Validation of simple indexes to assess insulin sensitivity during pregnancy in wistar and sprague-dawley rats. Am. J. Physiol. Endocrinol. Metab., 295: E1269-E1276. DOI: 10.1152/ajpendo.90207.2008

Chappell, L.C., P.T. Seed, A.L. Briley, F.J. Kelly and R. Lee et al., 1999. Effect of antioxidants on occurrence of pre-eclampsia in women at increased risk: A randomized trial. Lancet, 354: 810-816. DOI: 10.1016/S0140-6736(99)80010-5

Choi, K.C., S.Y. Lee, H.J. Yoo, O.H. Ryu and K.W. Lee et al., 2007. Effect of PPAR- $\delta$ agonist on the expression of visfatin, adiponectin and resistin in rat adipose tissue and 3T3-L1 adipocytes. Biochem. Biophys. Res. Commun., 357: 62-67. DOI: 10.1016/j.bbrc.2007.03.114

Conrad, K.P., T.M. Miles and D.F. Benyo, 1998. Circulating levels of immunoreactive cytokines in women with preeclampsia. Am. J. Reprod. Immunol., 40: 102-111. PMID: 9764352

Dekker, G.A. and B.M. Sibai, 1998. Etiology and pathogenesis of preeclampsia: Current concepts. Am. J. Obstet. Gynecol., 179: 1359-1375. DOI: 10.1016/S0002-9378(98)70160-7

Fasshauer, M. and R. Paschke, 2003. Regulation of adipocytokines and insulin resistance. Diabetologia, 46: 1594-1603. PMID: 14605806 
Fasshauer, M., T. Waldeyer, J. Seeger, S. Schrey and T. Ebert et al., 2008. Serum levels of the adipokine visfatin are increased in pre-eclampsia. Clin. Endocrinol., 69: 69-73. DOI: 10.1111/j.13652265.2007.03147.x

Fiore, G., P. Florio, L. Micheli, C. Nencini and M. Rossi et al., 2005. Endothelin-1 triggers placental oxidative stress pathways: Putative role in preeclampsia. J. Clin. Endocrinol. Metab., 90: 4205-4210. DOI: 10.1210/jc.2004-1632

Fukuhara, A., M. Matsuda, M. Nishizawa, K. Segawa and M. Tanaka et al., 2005. Visfatin: A protein secreted by visceral fat that mimics the effects of insulin. Science, 307: 426-430. PMID: 15604363

Gilbert, J.S., S.A. Babcock and J.P. Granger, 2007. Hypertension Produced by Reduced Uterine Perfusion in pregnant rats is associated with increased soluble Fms-Like tyrosine kinase-1 expression. Hypertension, 50: 1142-1147. DOI: 10.1161/HYPERTENSIONAHA.107.096594

Graepler, F., B. Verbeek, T. Graeter, I. Smirnow and H.L. Kong et al., 2005. Combined Endostatin/sFlt1 antiangiogenic gene therapy is highly effective in a rat model of HCC. Hepatology, 41: 879-886. DOI: 10.1002/hep.20613

Granger J.P., B.B. LaMarca, K. Cockrell, M. Sedeek and C. Balzi et al., 2006. Reduced Uterine Perfusion Pressure (RUPP) model for studying cardiovascular-renal dysfunction in response to placental ischemia. Methods Mol. Med., 122: 383-392. PMID: 16511995

Granger, J.P., 2004. Inflammatory cytokines, vascular function and hypertension. Am. J. Physiol. Regul. Integr. Comput. Physiol. 286: R989-R990. DOI: 10.1152/ajpregu.00157.2004

Grinspoon, S., 2006. Abnormal glucose regulation and treatment strategies for insulin resistance HIVinfected patients. Am. J. Infect. Dis., 2: 184-186. http://www.scipub.org/fulltext/ajid/ajid23184-186.pdf

Gulati, R., 2005. Raised serum TNF-alpha, blood sugar and uric acid in preeclampsia in third trimester of pregnancy. J. Nepal. Med. Assoc., 44: 36-38. PMID: 16554868

Hung, T.H., D.S. Charnock-Jones, J.N. Skepper and G.J. Burton, 2004. Secretion of tumor necrosis factor-alpha from human placental tissues induced by hypoxia-reoxygenation causes endothelial cell activation in vitro: A potential mediator of the inflammatory response in preeclampsia. Am. J. Pathol., 164: 1049-1061. PMID: 14982858

Huppertz, B. and J.C.P. Kingdom, 2004. Apoptosis in the trophoblast-role of apoptosis in placental morphogenesis. Reprod. Sci., 11: 353-362. DOI: 10.1016/j.jsgi.2004.06.002
Kirwan, J.P., S.H.D. Mouzon, J. Lepercq, J.C. Challier and L. Huston-Presley et al., 2002. TNF- $\alpha$ is a predictor of insulin resistance in human pregnancy. Diabetes, 51: 2207-2213. DOI: 10.2337/diabetes.51.7.2207

LaMarca, B.B.D., W.A. Bennett, B.T. Alexander, K. Cockrell and J.P. Granger, 2005a. Hypertension produced by reductions in uterine perfusion in the pregnant rat: Role of tumor necrosis factor- $\alpha$. Hypertension, 46: 1022-1025. DOI: 10.1161/01.HYP.0000175476.26719.36

LaMarca, B.B., K. Cockrell, E. Sullivan, W. Bennett and J.P. Granger, 2005b. Role of endothelin in mediating tumor necrosis factor-induced hypertension in pregnant rats. Hypertension, 46: 82-86. DOI: 10.1161/01.HYP.0000169152.59854.36

Li, G.Y., B. Fan, Y.Z. Wu, X.R. Wang and Y.H. Wang et al., 2005. Inhibition of vascular endothelial growth factor gene expression by T7siRNAs in cultured human retinal pigment epithelial cells. Chinese Med. J., 118: 567-573. PMID: 15820087

Losonczy, G., G. Brown and R.C. Venuto, 1992. Increased peripheral resistance during reduced uterine perfusion pressure hypertension in pregnant rabbits. Am. J. Med. Sci., 303: 233-240. PMID: 1562040

Lu, F., M. Longo, E. Tamayo, W. Maner and A. AlHendy et al., 2007. The effect of over-expression of sFlt-1 on blood pressure and the occurrence of other manifestations of preeclampsia in unrestrained conscious pregnant mice. Am. J. Obstet. Gynecol., 196: 396.e1-396.e7. DOI: 10.1016/j.ajog.2006.12.024

Ma, Y., Y. Cheng, J. Wang, H. Cheng and S. Zhou et al., 2010. The changes of visfatin in serum and its expression in fat and placental tissue in pregnant women with gestational diabetes. Diabetes Res. Clin. Pract., 90: 60-65. DOI: 10.1016/j.diabres.2010.06.010

Matthews, D.R., J.P. Hosker, A.S. Rudenski, B.A. Naylor and D.F. Treacher et al., 1985. Homeostasis model assessment: insulin resistance and $\beta$-cell function from fasting plasma glucose and insulin concentrations in man. Diabetologia, 28: 412-419. DOI: $10.1007 / \mathrm{BF} 00280883$

Maynard, S.E., J.Y. Min, J. Merchan, K.H. Lim and J. Li et al., 2003. Excess placental soluble Fms-like tyrosine kinase 1 (sFlt1) may contribute to endothelial dysfunction, hypertension and proteinuria in preeclampsia. J. Clin. Invest., 111: 649-658. DOI: 10.1172/JCI200317189 
Netea, M.G., J.P.H. Drenth, N. De Pont, A. Hijmans and M. Keuter et al., 1996. A semi-quantitative reverse transcriptase polymerase chain reaction method for measurement of mRNA for TNF $\alpha$ and IL-1 $\beta$ in whole blood cultures: Its application in typhoid fever and exentic exercise. Cytokine, 8: 739-744. DOI: 10.1006/cyto.1996.0098

Parrish, M.R., S.R. Murphy, S. Rutland, K. Wallace and K. Wenzel et al., 2010. The effect of immune factors, tumor necrosis factor- $\alpha$ and agonistic autoantibodies to the angiotensin II type I receptor on soluble Fms-like tyrosine-1 and soluble endoglin production in response to hypertension during pregnancy. Am. J. Hypertens., 23: 911-916. DOI: 10.1038/ajh.2010.70

Roberts, J.M., G. Pearson, J. Cutler and M. Lindheimer, 2003. Summary of the NHLBI working group on research on hypertension during pregnancy. Hypertension, 41: 437-445. DOI: 10.1161/01.HYP.0000054981.03589.E9

Scherrer, U. and C. Sartori, 1997. Insulin as a vascular and sympathoexcitatory hormone: Implications for blood pressure regulation, insulin sensitivity and cardiovascular morbidity. Circulation, 96: 4104-4113. PMID: 9403636
Sedeek, M., J.S.Gilbert, B.B. LaMarca, M. Sholook and D.L. Chandler et al., 2008. Role of reactive oxygen species in hypertension produced by reduced uterine perfusion in pregnant rats. Am. J. Hypertens., 21: 1152-1156. DOI: 10.1038/ajh.2008.239

Sibai, B., G. Dekker and M. Kupferminc, 2005. Preeclampsia. Lancet, 365: 785-799. DOI: 10.1016/S0140-6736(05)17987-2

Thadhani, R., J.L. Ecker, W.P. Mutter, M. Wolf and K.V. Smirnakis et al., 2004. Insulin resistance and alterations in angiogenesis: Additive insults that may lead to preeclampsia. Hypertension, 43: 988-992. DOI: 10.1161/01.HYP.0000124460.67539.1d

Wolf, M., L. Sandler, K. Munoz, K. Hsu and J.L. Ecker et al., 2002. First trimester insulin resistance and subsequent preeclampsia: A prospective study. J. Clin. Endocrinol. Metab., 87: 1563-1568. DOI: 10.1210/jc.87.4.1563

Zareian, P., A.S. Jahromi, F.H. Rad and S. Zarei, 2010. Do resistin and tumor necrosis factor- $\alpha$ relate to changes in insulin resistance in normal pregnancy? Am. J. Biochem. Biotechnol., 6: 19-24. http://www.scipub.org/fulltext/ajbb/ajbb6119-24.pdf 